НАУКИ О ЗЕМЛЕ

"НАУКА. ИННОВАЦИИ. ТЕХНОЛОГИИ", № 3, 2019

25.00 .35

ГЕОИНФОРМАТИКА

УДК 528.94

Игонин А.И.,

Тикунов В.С.

geoigonin@gmail.com

vstikunov@yandex.ru

Московский государственный университет имени М.В. Ломоносова

\title{
МАТЕМАТИКО-КАРТОГРАФИЧЕСКОЕ МОДЕЛИРОВАНИЕ И КАРТОГРАФИРОВАНИЕ ДЕМОГРАФИЧЕСКОЙ СИТУАЦИИ В РЕГИОНАХ ЕВРОПЫ И РОССИИ
}

Введение. $\quad$ В работе описывается методика применения алгоритма математикокартографического моделирования типологических карт для разработки типологии демографической ситуации и применения этих инструментов для геодемографического исследования и мониторинга обширной территории. Формирование обоснованных представлений ○ дифференциации геодемографического пространства дает возможность оперативно сигнализировать о требуемых изменениях в демографической политике и социально-экономических преобразо-

Материалы и методы ваниях конкретной территории.

исследования. В рамках исследования демографического развития стран Европы и России разработаны три варианта типологии на базе различных наборов показателей. произведено моделирование тематического содержания трех серий типологических карт за период с 2005 по 2016 годы. Для этих целей использовался алгоритм многовариантной типологии для гомогенных территориальных единиц, объединяемых в группы (таксоны). Результаты исследований

и их обсуждение. Многовариантная типология дала неоднородные результаты, что позволяет оценивать широкий спектр территориальных особенностей демографических характеристик населения и выявлять закономерности их распределения. Так, для типологии по второму варианту вместо показателя ожидаемой продолжительности жизни применен общий коэффициент смертности, что усиливает значение данной разработки для анализа демографического движения населения и дает более четкое представление о причинах и генезисе динамики демографической ситуации. В данном конкретном случае расчеты коэффициента неоднородности показали, что таксонов следует выделить пять

Выводы. Разработанная математико-картографическая модель типологии регионов Европы и России по трем наборам показателей демографического развития позволяет увидеть пространственные закономерности демографического развития территории и рассмотреть новые грани территориальной дифференциации рассматриваемых регионов.

Ключевые слова: Демографическая ситуация, математико-картографическое моделирование, типология, Россия, Европа. 
Igonin A.I.,

Tikunov V.S

Materials and methods of research.

Results of research and discussion.

Conclusions.

Keywords:

Introduction

geoigonin@gmail.com

vstikunov@yandex.ru

Lomonosov Moscow State University

\section{MATHEMATICAL-CARTOGRAPHIC MODELING AND CARTOGRAPHY OF DEMOGRAPHIC SITUATION IN THE REGIONS OF EUROPE AND RUSSIA}

The paper describes the methodology for applying the algorithm of mathematical cartographic modeling of typological maps to develop a typology of the demographic situation and the use of these tools for geodemographic research and monitoring of a vast territory. The formation of sound ideas about the differentiation of geodemographic space makes it possible to quickly signal the required changes in the demographic policy and socio-economic transformations of a particular territory.

In the framework of the study of the demographic development of the countries of Europe and Russia, three typologies were developed based on various sets of indicators. The thematic content of three series of typological maps for the period from 2005 to 2016 was modeled. For these purposes, a multivariate typology algorithm was used for homogeneous territorial units, united into groups (taxa).

The multivariate typology gave heterogeneous results, which makes it possible to assess a wide range of territorial features of the demographic characteristics of the population and identify patterns of their distribution. So, for the typology of the second option, instead of the indicator of life expectancy, the general mortality rate was used, which strengthens the significance of this development for the analysis of the demographic movement of the population and gives a clearer idea of the causes and genesis of the dynamics of the demographic situation. In this particular case, calculations of the heterogeneity coefficient showed that five taxa should be distinguished.

The developed mathematical-cartographic model of the typology of the regions of Europe and Russia for three sets of indicators of demographic development allows us to see the spatial patterns of the demographic development of the territory and consider new facets of the territorial differentiation of the regions under consideration.

demographic situation, mathematical-cartographic modeling, typology, Russia, Europe.

\section{Введение}

Разработка и применение географической информационной системы (ГИС) для исследования и мониторинга демографического развития подразумевает сбор, анализ и интерпретацию данных демографической статистики. Математико-картографическое моделирование системообразующий метод работы с базой данных ГИС. Для реализации этого метода существует ряд алгоритмов.

В данной работе описывается методика применения алгоритма математико-картографического моделирования типологических карт для разработ- 
ки типологии демографической ситуации и применения этих инструментов для геодемографического исследования и мониторинга обширной территории. Типология позволяет получить сравнительные оценочные характеристики для рассматриваемых территорий. Формирование обоснованных представлений о дифференциации геодемографического пространства дает возможность оперативно сигнализировать о требуемых изменениях в демографической политике и социально-экономических преобразованиях конкретной территории.

Цель работы - разработать варианты типологии демографической ситуации регионов Европы и России с помощью реализации алгоритма для моделирования тематического содержания типологический карт, оценить территориальную дифференциацию демографической обстановки на территории северной Евразии. Потребовалось решить ряд задач. Обновить и адаптировать базу данных демографических показателей Европы и азиатской части России, с последуюшим формированием требуемьх наборов показателей, характеризующих демографическое состояние регионов. Создать многомерную математическую модель демографической ситуации при трех наборах показателей. Разработать серию карт демографической ситуации и ее динамики в среде ГИС. Оценить и интерпретировать результаты типологии.

\section{Материалы и методы исследований}

Классификация производилась на основе данных по территориальным единицам уровня NUTS-2 (регионы второго уровня - «средней величины») для стран Европы [8] и субъектов федерации для России [4]. Сформирована база данных из основных демографических показателей за период с 2005 по 2016 годы. По каждому из показателей актуализированы данные за 11 лет. К году написания статьи (2019) по многим регионам данные собраны до 2018 года включительно, но поскольку нет полного сопоставимого охвата данными рассматриваемой территории, для типологии решено использовать период до 2016 года включительно с данными по всем интересуемым регионам. Работа проводилась в среде ранее созданной ГИС «Демографического развития Европы и Азиатской части России» [1], где сформирована открытая система сбора данных для мониторинга демографических изменений и отдельный раздел моделирования геодемографической композиции. На данном этапе исследования использованы ряды 48 уникальных показателей. Для целей классификации использованы показатели суммарного коэффициента рождаемости, общий коэффициент смертности, ожидаемая продолжительность жизни, сальдо миграции и коэффициент изменения численности населения [2]. 
В рамках исследования демографического развития стран Европы и России разработаны три варианта типологии на базе различных наборов показателей [5]. В первый вариант включены показатели суммарного коэффициента рождаемости, ожидаемой продолжительности жизни и коэффициент изменения численности населения, такое сочетание позволяет оценить одновременно особенности естественного движения, возрастной структуры и общего изменения численности населения. Для расчета второго варианта использованы показатели суммарного коэффициента рождаемости, общего коэффициента смертности и коэффициента изменения численности населения, то есть конкретные данные по интенсивности процессов естественного движения и общих изменений численности, рассмотрение показателей в таком составе дает возможность оценить вклад естественного движения населения в его общую динамику. В третьем варианте расчета общий коэффициент смертности заменен на показатель миграционного баланса, что формирует базу для типологии территориальных единиц в ракурсе миграционного фактора демографического развития.

На основе описанного набора показателей произведено моделирование тематического содержания трех серий типологических карт за период с 2005 по 2016 годы [6, 7]. Для этих целей использовался алгоритм многовариантной типологии для гомогенных территориальных единиц, объединяемых в группы (таксоны) [3].

На первом этапе произведена нормировка исходных показателей по дисперсиям:

$$
\begin{aligned}
& \hat{\mathrm{x}}_{i j}=\frac{x_{i j}-\bar{x}_{J}}{\sigma_{j}}, i=1,2,3, \ldots, n ; j=1,2,3, \ldots, m ; \\
& \bar{x}_{j}=\frac{1}{n} \sum_{i=1}^{n} x_{i j} ; \sigma_{j}=\sqrt{\frac{1}{n} \sum_{i=1}^{n}\left(x_{i j}-\bar{x}_{j}\right)^{2}}
\end{aligned}
$$

Нормированные показатели $\hat{\mathbf{x}}$ представляются в виде матрицы для расчета евклидовых расстояний $\left(d_{i k}\right)$, соединяюших каждую пару включенных в расчет участков границ и отражающих их различия:

$$
d_{i k}=\sqrt{\sum_{j=1}^{m}\left(\hat{x}_{i j}-\hat{x}_{k j}\right)^{2}}, i=1,2,3, \ldots, n ; j=1,2,3, \ldots, m ;
$$

При типологической классификации из полученных значений $d_{i k}$ выбирается наибольшее расстояние, а две территориальные единицы, которые оно связывает, становятся ядрами однородных типов (таксонов). Таксоны формируются распределением остальных регионов между двумя ядрами по минимальности евклидовых расстояний. В случае выделения большего числа таксонов, для выделения третьего ядра и всех последующих каждую из всех оставшихся территориальных единиц подставляют в виде ядра, а 
остальные распределяются между тремя ядрами по минимальности $d_{i k}$ и находится вариант с наименьшими внутригрупповыми различиями. На втором этапе (при формировании трех групп) алгоритм работает следующим образом. Два первых ядра остаются, а третье находится так. Каждая из (n-2) оставшихся территориальных единиц опробуется как третье ядро, a (n-3) остающиеся - распределяются между тремя ядрами по минимальности евклидовых расстояний. Для каждого варианта группировки подсчитывается сумма внутригрупповых различий и тот вариант, который дает наименьшую сумму, принимается в качестве окончательного для трехгруппового деления, а территориальная единица, служившая ядром, фиксируется как окончательное третье ядро.

Процедура продолжается аналогично для формирования четырех, пяти, шести и т. д. однородных групп. Причем на каждом шаге определяется новое ядро и формируется новая группировка. В пределе можно получить $n$ групп, однако для практических целей этого не требуется и устанавливается рубеж $l_{\max }$, исходя из логических соображений. Аналогично количество групп, которые следует анализировать можно ограничить и снизу $l_{\min }$.

Получаемый ряд группировок можно анализировать на основе абсолютного и относительного коэффициентов неоднородности и с их помощью выбирать оптимальное количество таксонов:

$$
\begin{gathered}
A_{k}=\frac{100\left\{\sum_{k=1}^{K} \sum_{j=1}^{n} \sum_{i=1}^{n}\left[\sum_{p=1}^{P}\left(x_{i p}-x_{j p}\right)^{2}\right]^{1 / 2} I_{i k} I_{j k}\right\}}{\sum_{i=1}^{t_{\max }}\left[\sum_{p=1}^{P}\left(x_{i p}-x_{j p}\right)^{2}\right]^{1 / 2}}, \\
\mathbf{k}=t_{\min }, t_{\min }+1, \ldots, t_{\max } ; \\
O_{k}=\frac{100\left\{\sum_{k=1}^{K} \sum_{j=1}^{n} \sum_{i=1}^{n}\left[\sum_{p=1}^{P}\left(x_{i p}-x_{j p}\right)^{2}\right]^{1 / 2} I_{i k} I_{j k}\right\}}{\sum_{i=1}^{t_{\max }} \sum_{j=1}^{n} \sum_{i=1}^{n}\left[\sum_{p=1}^{P}\left(x_{i p}-x_{j p}\right)^{2}\right]^{1 / 2} I_{i k} I_{j k}}, \\
\mathrm{k}=t_{\min }, t_{\min }+1, \ldots, t_{\max }-1 .
\end{gathered}
$$

Резкое возрастание значений $A_{k}$ или $O_{k}$ при уменьшении числа выделяемых таксонов свидетельствует о повышении неоднородности внутри выделенных кластеров, и, напротив, плавное возрастание коэффициентов - признак равномерного ее увеличения. Порог, за которым следует резкое повышение неоднородности оптимально принимать за окончательное число таксонов.

Следует заметить, что вместо евклидовых расстояний можно использовать коэффициенты корреляции (или величины равные 1-r, где r - разнообразные коэффициенты корреляции), показатели ассоциации или иные 
меры расстояний. Весь набор мер различия не эквивалентен между собой, то есть их использование может привести к различающимся результатам. Поэтому в конкретных экспериментах полезно опробовать ряд мер, но не перебирая их всех, для чего следует предварительно выделить эквивалентные меры.

Полученные результаты удобно анализировать по среднеарифметическим значениям каждого показателя, относительно всех территориальных единищ, входящих в тот или иной таксон. В ряде случаев целесообразно нахождение экстремальных значений в каждом таксоне по всем исходным показателям. Эти характеристики можно применять для смысловой характеристики таксонов.

Данный алгоритм типологии производит классификацию при условии гомогенности территориальных единиц, объединяемых в таксоны. Однако, в некоторых случаях необходимо условие не только гомогенности, но и максимальной гетерогенности ядер, служащих как бы эталонами для формирования таксонов.

Алгоритм реализован для каждого из трех вариантов сочетания показателей, что привело к формированию трех моделей на каждый год мониторинга. Для содержательного анализа предпочтительно представлять варианты классификаций в виде карт. Все пути моделирования позволяют картографировать их результаты, для этого использованы карты со ступенчатыми шкалами.

\section{Результаты исследований и их обсуждение}

Многовариантная типология дала неоднородные результаты, что позволяет оценивать широкий спектр территориальных особенностей демографических характеристик населения и выявлять закономерности их распределения. Обширный массив данных позволяет оценивать изменение демографической ситуации с 2005 по 2016 годы. В данной работе представлены типологические сюжеты за 2016 год, по наиболее актуальным данным одновременно на всю исследуемою территорию. Особенности динамики демографических характеристик населения в разрезе рассматриваемых территориальных единиц и типов демографической ситуации будут рассмотрены в следующих работах.

При типологии по показателям суммарного коэффициента рождаемости, ожидаемой продолжительности жизни и коэффициента динамики численности населения резкое возрастание значений абсолютного коэффициента неоднородности при переходе от четырех групп к трем свидетельствует о существенном повышении неоднородности внутри выделенных таксонов. Поскольку порог, за которым следует резкое возрастание коэффициента неод- 

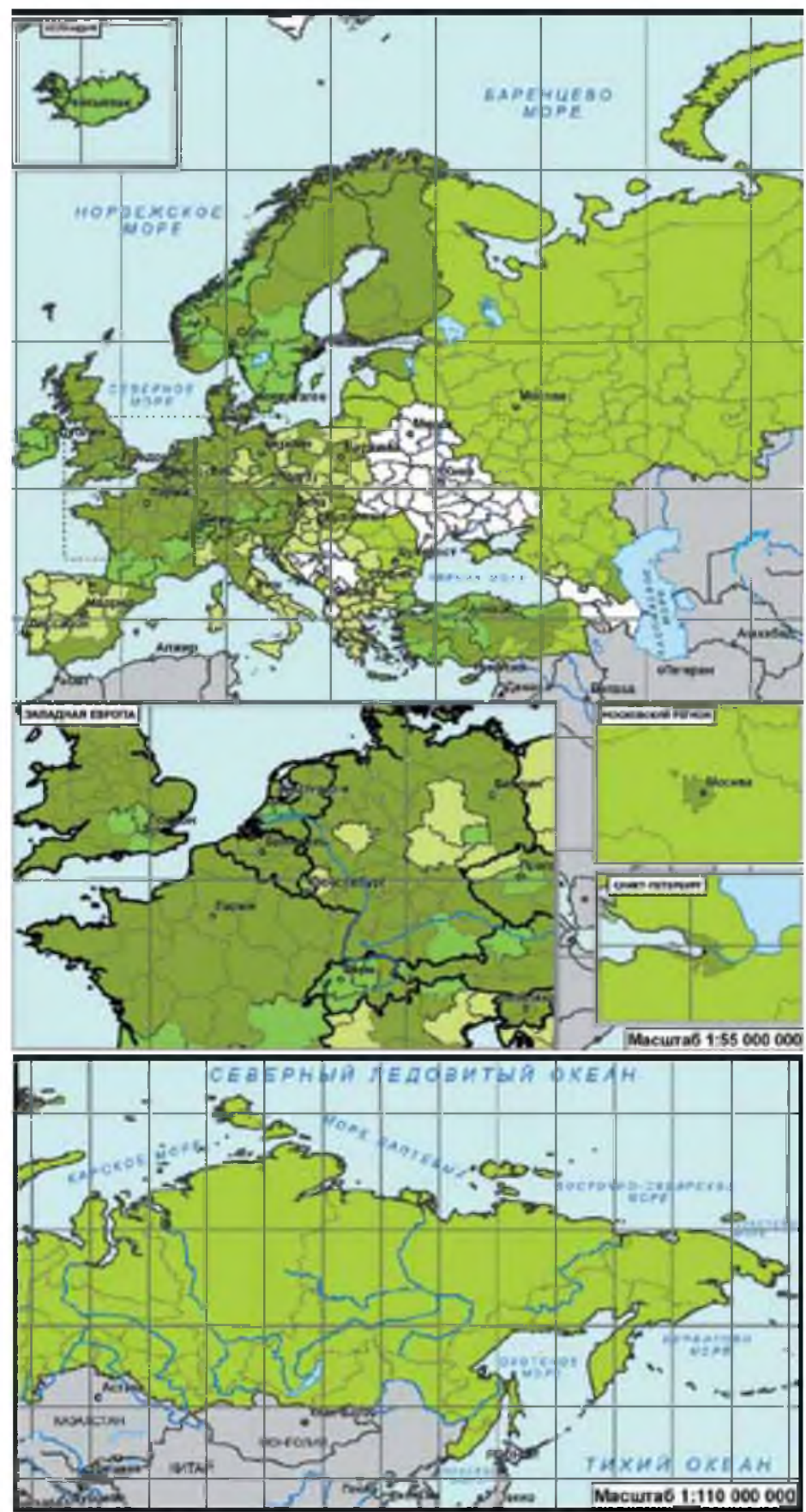

Типология демографической ситуации (2016 год, Вариант 1)

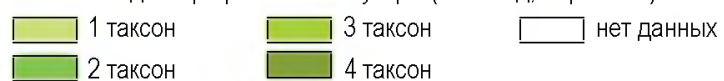

Pис. 1.

Типология демографической ситуации, Вариант 1.

Fig. 1. Typology of the demographic situation, Option 1. 
нородности равен четырем, такое число таксонов целесообразно принять за окончательное число.

В первый таксон вошли территориальные единицы с низкими показателями рождаемости (среднеарифметическое значение - 1,37), средними показателями ожидаемой продолжительности жизни (среднеарифметическое 79,93 года) и интенсивным снижением численности населения (среднеарифметическое - $-3,92 \%$ ). Демографическая ситуация в таких регионах неблагоприятная, крайне низкий уровень рождаемости способствует снижению численности населения, а миграционный обмен не только не восполняет численность, а скорее усиливает депопуляцию. Такая обстановка сложилась в Португалии, на западе и в центре Испании, на юге Италии и в ряде регионов севера страны, во всех регионах Греции, кроме Крита. Это обусловлено тем, что население Средиземноморья продолжает стареть, рождаемость стабилизировалась на минимальных для Европы, да и всего мира значениях, а миграционные потоки направлены в наиболее развитые центры и регионы транзитом через слаборазвитые регионы юга. Похожая ситуация сложилась и в регионах Восточной Европы относящихся к данному таксону выстроившихся в меридиональном направлении от Западно-Поморского воеводства в Польше до Адриатической Хорватии.

Довольно пестрый состав регионов выделен во второй таксон с не самой высокой рождаемостью $(1,78)$, высокой продолжительностью жизни $(81,1$ лет) и наиболее интенсивным увеличением численности населения $(11,63 \%$ ). Сюда вошли как регионы где основным фактором увеличения численности населения является рождаемость - западная и северная Турция, Ирландия, Ингушетия, так и регионы с высокой миграционной привлекательностью, где фактор миграции влияет на численность сопоставимо с естественным движением - регионы Швейцарии и южной Норвегии, или является определяющим регионы южной Франции, южной Швеции, Обербайерн в Германии и Прага в Чехии.

Большинство регионов России по этой типологии вошли в третий таксон. Где сочетаются относительно высокие показатели суммарного коэффициента рождаемости (среднеарифметическое 1,9), низкие показатели ожидаемой продолжительности жизни (71,9 лет) и в среднем слабоинтенсивная убыль населения $(-0,91 \%)$. Кроме российских регионов к этому таксону отнесены юго-восточные регионы Турции, где происходит интенсивный миграционный отток, что при высокой рождаемости балансирует изменение численности. Также убыль населения при невысокой продолжительности жизни отмечается в восточных регионах Румынии и Венгрии, в Болгарии, Латвии и Литве.

Четвертый таксон объединил регионы с невысокой интенсивностью рождаемости $(1,62)$, высокой ожидаемой продолжительностью жизни $(81,37)$ и слабоинтенсивным ростом численности населения $(3,2 \%$ ). В данной ти- 

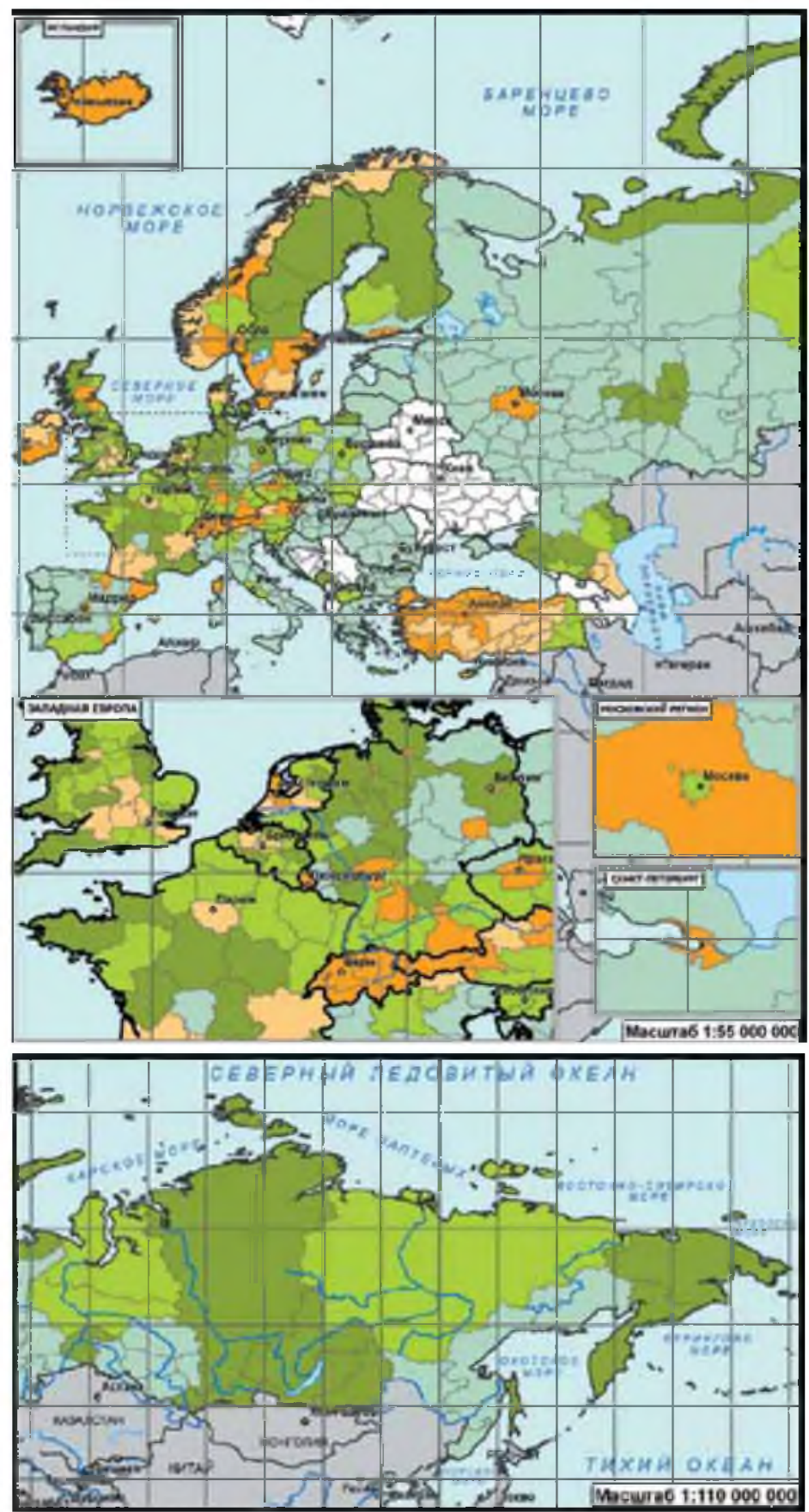

Типология демографической ситуации (2016 год, Вариант 2)

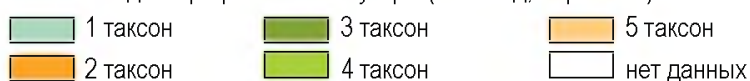

Pис. 2.

Типология демографической ситуации, Вариант 2.

Fig. 2. Typology of the demographic situation, Option 2 
пологии это регионы с наиболее благоприятной демографической обстановкой по критериям умеренного роста населения и высокой продолжительности жизни. В основном это регионы Западной Европы где невысокие показатели естественного прироста, а иногда и убыли населения, восполняются положительным миграционным сальдо. Также сюда можно отнести регионы Северной Европы и наиболее развитые регионы Средиземноморья - побережье Испании, французский Прованс, центральная и северная Италия.

Для типологии по второму варианту вместо показателя ожидаемой продолжительности жизни применен общий коэффициент смертности, что усиливает значение данной разработки для анализа демографического движения населения и дает более четкое представление о причинах и генезисе динамики демографической ситуации. В данном конкретном случае расчеты коэффициента неоднородности показали, что таксонов следует выделить пять.

Первый таксон объединяет регионы с наименее благоприятной демографической ситуацией, в большинстве из них отмечается снижение численности населения (среднеарифметическое - $-3,92 \%$ ), относительно высокая смертность $(12,84 \%$ и) и низкая рождаемость (суммарный коэффициент - 1,53). Это большинство регионов Европейской территории России, юга Западной Сибири за исключением Тюменской области и округов, регионы Дальнего Востока. Сюда также отнесены регионы Прибалтики, все регионы Венгрии, Румынии и Греции, часть регионов Польши, Чехии и восточной Германии, а также большая часть регионов Италии, Португалии, центральной и западной Испании.

Во втором типе объединены регионы с высокими темпами прироста населения $(12,9 \%)$ при низкой рождаемости $(1,61)$ и смертности $(8,03 \%)$, то есть регионы высокой миграционной привлекательности. Так западные и северные регионы Турции, где демографических переход практически завершен увеличивают численность в основном за счет миграции из восточных и южных регионов. Основная часть таких регионов - это крупные города и агломерации, такие как Москва, Санкт-Петербург, Мадрид, Прага, Вена, Амстердам, а также территории с высоким уровнем жизни - Швейцария, предальпийские регионы Германии, западная Австрия, южные норвежские и шведские регионы.

Оставшиеся типы объединяют регионы с относительно благоприятной демографической ситуацией, умеренным влиянием миграционного фактора, средней и относительно высокой рождаемостью. К третьему типу относятся регионы со сравнительно высокими показателями как смертности (среднеарифметическое $11,2 \%$ ), так и рождаемости $(1,85)$ со стабильной или слаборастущей численностью населения (2,8\%). Такая обстановка сложилась в периферийных регионах Великобритании, во Франции от Бретани до Прованса, в Западной Германии, а также в Бранденбурге, на севере Швеции. Похожие демографические характеристики отмечаются на территории России в 

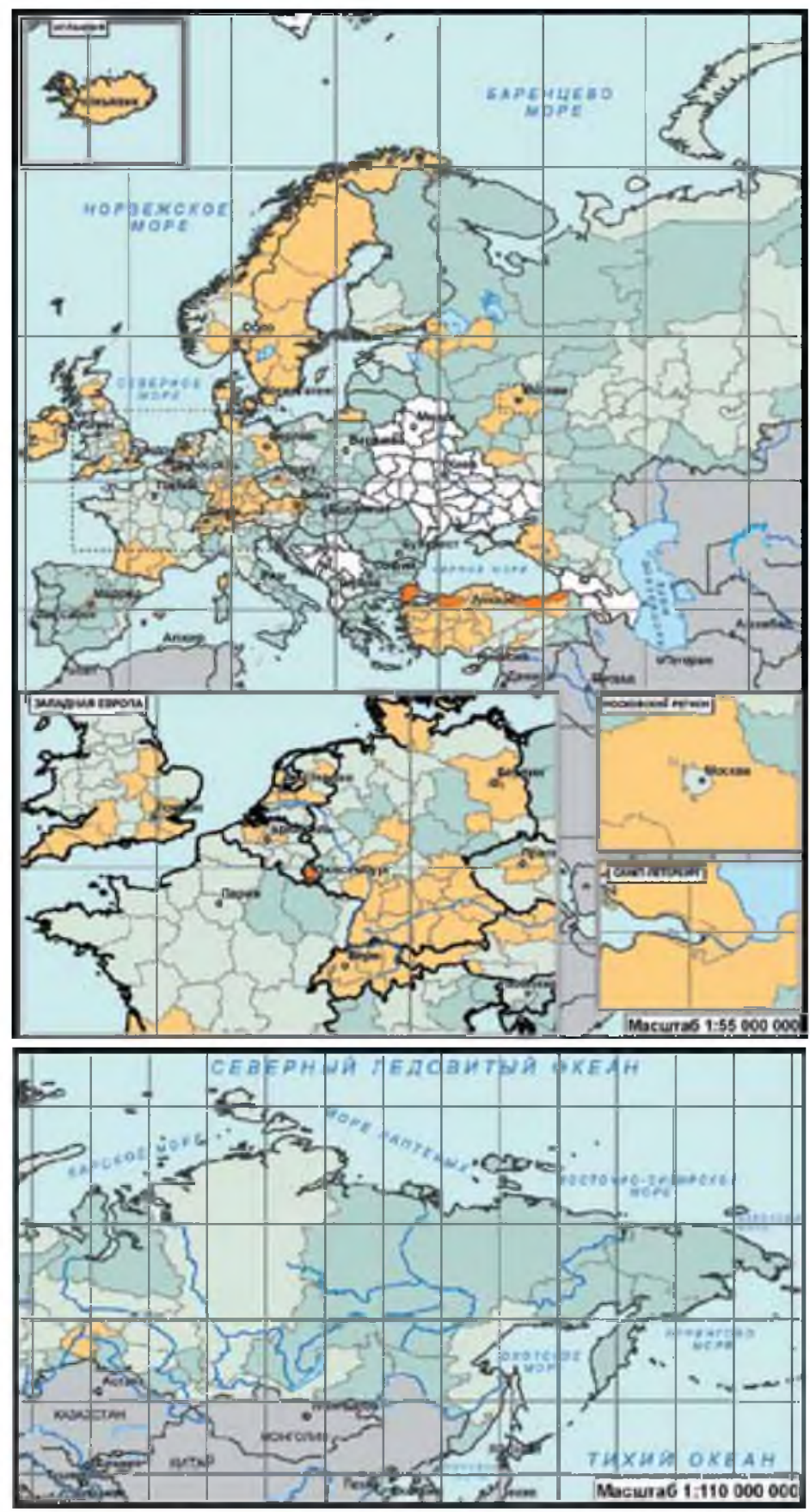

Типология демографической ситуации (2016 год, Вариант 3)

$\begin{array}{ll}\square & 1 \text { таксон } \\ \square & \square \text { таксон } \\ \square & 3 \text { таксон }\end{array}$

Pис. 3.

Типология демографической ситуации, Вариант 3.

Fig. 3. Typology of the demographic situation, Option 3. 
Адыгее, Ставропольском и Краснодарском краях, в приволжских республиках Марий Эл, Удмуртии и Татарстане, в регионах Восточной Сибири.

Четвертый таксон объединяет регионы находящиеся в Западной и Центральной Европе. Невысокая рождаемость здесь сочетается со средней смертностью и незначительным ростом численности населения. Сюда также отнесены три региона восточной Турции, где при относительно высоких показателях естественного прироста численность населения не растет в связи с миграционным оттоком.

Пятый тип включает регионы с демографическими установками на рост численности населения и высокими показателями рождаемости $(2,03 \%)$ и роста численности $(9,66 \%)$ при низкой смертности. Такие значения достигаются за счет благоприятной половозрастной структуры населения и миграционного притока рабочей силы в трудоспособных возрастах. Регионы данного типа находятся в центре Англии, Нидерландов, на юго-западе Франции. А в регионах центральной и восточной Турции, в Чечне и Дагестане, определяющий фактор положительной динамики численности населения по-прежнему высокая рождаемость при низкой смертности.

Типология по сочетанию показателей рождаемости, миграционного сальдо и коэффициента изменения численности населения во многом дополняет второй вид типологии и открывает возможности многостороннего анализа влияния миграционного фактора на демографические характеристики населения. Первый тип включает регионы с низкой рождаемость $(1,53)$, но быстрым ростом численности населения (21,6 \%) обусловленным высоким положительным сальдо миграции (18,8\%). Классическим примером данного типа является город Берлин, кроме него сюда входят Вена, Канарские, Балеарские острова, северные Эгейские острова, Люксембург, а таюже три северных региона Турции.

Второй тип составляют регионы с низкой рождаемостью $(1,58)$, отрицательным миграционным сальдо $(-2,65 \%)$ и убылью населения $(-3,92 \%)$. Этот тип по большинству регионов Европы совпадает с первым таксоном первого варианта, а также российские и турецкие регионы третьего таксона. В общем это сильно постаревшие регионы Средиземноморья, где стабильная естественная убыль (кроме регионов Турции) усугубляется отрицательным миграционным сальдо. Ключевыми в рамках территориального анализа здесь следует обозначить западные регионы Пиренейского полуострова, южные регионы Италии, регионы Юго-Восточной Европы, Европейски Север России, регионы Восточной Сибири и Дальнего Востока.

Третий тип характеризуется относительно высокой рождаемостью $(1,76)$ и интенсивным миграционным приростом $(7,4 \% 0)$, что определяет высокие показатели роста численности населения $(10,1 \%$ ). К ключевым территориальным сегментам данного таксона отнесены приальпийские и альпийские регионы Германии, Австрии и Швейцарии, Ирландия, южная и централь- 
ная Англия, Швеция, западные регионы Турции, Московский и Санкт-Петербургский регионы и Краснодарский край.

Демографическими особенностями четвертого типа являются высокая рождаемость $(1,77)$ при незначительном миграционном приросте $(1,67 \%)$ и общем росте численности населения $(2,75 \%)$ с определяющим влиянием естественного движения. Такая демографическая композиция сложилась в остальных регионах Западной и Северной Европы, также в центре Турции, в Приволжье, на Урале, а также в ряде регионов Сибири и Северного Кавказа. Регионы данного типа различаются по многим особенностям демографического развития, но в данном случае определяющие критерии объединения в один таксон это сочетание трех ключевых показателей, которые позволяют дать представление о динамике численности населения и соотношении естественного и механического движения. Без подробного рассмотрения конкретных особенностей и факторов формирования демографической ситуации в регионах одного таксона, нельзя с точностью сказать, что они развиваются по похожему сценарию. Типология не является самоцелью исследования, а используется как инструмент для выявления территориальных закономерностей демографического развития территории.

\section{Выводы}

Результаты типологии позволяют сделать следующие выводы. Во-первых, часто это результаты, которые соответствуют интуитивным представлениям о территориальной дифференциации демографических характеристик населения Европы и России. Во-вторых, это результаты корректирующие и конкретизирующие прежние представления. В-третьих, это результаты, которые сложно объяснить сложившимися представлениями, они отличаются от предварительных прогнозов. В-четвертых, все расхождения с субъективными представлениями важнейший материал для формирования новых направлений исследований.

Разработанная математико-картографическая модель типологии регионов Европы и России по трем наборам показателей демографического развития позволяет увидеть пространственные закономерности демографического развития территории и рассмотреть новые грани территориальной дифференциации рассматриваемых регионов.

В данной работе обширный массив данных мониторинга демографического развития с помощью методов математико-картографического моделирования преобразован в конкретный результат - набор тематических карт и их интерпретаций. В продолжении этого исследования в рамках изучения территориальной дифференциации демографических процессов требуется подробно рассмотреть динамику показателей по имеющейся базе данных, 
чтобы выяснить причины формирования и трансформации демографической ситуации, выявить сдвиги геодемографической композиции, подробно описать типичные регионы и переход регионов из одной группы в другую, выяснить его генезис.

Применение алгоритмов типологической классификации на такую обширную территорию, мониторинг изменений в типах и таксонах помогает решать задачу принятия решений в рамках изменения демографической политики в связи со сдвигами пространственных закономерностей демографического развития территорий. Многовариантный подход к типологии, в том числе по набору показателей позволяет выполнять качественную оценку процессов и их изменений, выявлять скрытые особенности и различия в демографической ситуации.

Рукопись поступила в редакцию 10.08.2019, принята к публикации 02.09.2019.

\section{Библиографический список}

1. Игонин А.И. Создание справочно-аналитической геоинформационной системы мониторинга демографического развития Европы и Азиатской части России: автореф. дис. ... на соиск. уч. ст. канд. геогр. Наук М.: МГУ имени М.В. Ломоносова, 2012. 26 с.

2. Практическая демография / под ред. Л.Л. Рыбаковского. М.: ЦЦСП, 2005. 280 C.

3. Тикунов В.С. Классификации в географии: ренессанс или увядание? (Опыт формальных классификаций). М.; Смоленск: изд СГУ. 1997. 367 c.

4. Демография. http://www.gks.ru/wps/wcm/connect/rosstat_main/ rosstat/ru/statistics/population/demography/ (Дата обращения: 16.03.2019).

5. Harris R., Johnston R., Burgess S. Neighborhoods, Ethnicity and School Choice: Developing a Statistical Framework for Geodemographic Analysis // Popul Res Po- licy Rev. 2007. No26. P. 553-579.

6. Horn M., Köppen B. Demographischer Wandel in Deutschlanddie lokale und regionale Perspektive. Universität Koblenz-Landau, 2007. P. 13-35.

7. Singleton A., Longley P. Geodemographics, visualisation, and social networks in applied geography // Applied Geography. 2009. No29. P. 289-298.

8. Total fertility rate by NUTS 2 region URL: https://ec.europa.eu/eurostat/data/database?node_code=tgs00062 (Дата обращения: 12.03.20199. Conception statistics, England and Wales https:// www.ons.gov.uk/peoplepopulationandcommunity/birthsdeathsandmarriages/conceptionandfertilityrates/datasets/conceptionstatisticsenglandandwalesreferencetables (Дата обращения: 19.03.2019) 


\section{References}

1. Igonin A.I. Creation of a reference and analytical geographic information system for monitoring the demographic development of Europe and the Asian part of Russia: Abstract. dis. M.: Lomonosov Moscow State University, 2012. 26 p.

2. Practical demography / Edited by L. L. Rybakovsky. M.: TSSP, 2005. $280 \mathrm{PP}$

3. Tikunov V. S. Classifications in geography: Renaissance or fading? (The experience of formal classifications) - Moscow-Smolensk: Publishing house. Smolensk State University. 1997. 367 c.

4. Demography http://www.gks.ru/wps/wcm/connect/rosstat_main/ rosstat/ru/statistics/population/demography/ (accessed: 16.03. 2019).

5. Harris R., Johnston R., Burgess S. Neighborhoods, Ethnicity and School Choice: Developing a Statistical Framework for Geodemographic Analysis // Popul Res Po- licy Rev. 2007. No26. P. 553-579.

6. Horn M., Köppen B. Demographischer Wandel in Deutschland die lokale und regionale Perspektive. Universität Koblenz-Landau, 2007. P. 13-35

7. Singleton A., Longley P. Geodemographics, visualisation, and social networks in applied geography // Applied Geography. 2009. No29. P. 289-298.

8. Total fertility rate by NUTS 2 region URL: https://ec. europa.eu/eurostat/data/database?node_code $=\operatorname{tgs} 00062$ (accessed:: 12.03.2019).

9. Conception statistics, England and Wales https://www.ons.gov.uk/ peoplepopulationandcommunity/birthsdeathsandmarriages/conceptionandfertilityrates/datasets/conceptionstatisticsenglandandwalesreferencetables (accessed: 19.03.2019)

\section{O6 авторах}

Игонин Александр Иванович, кандидат географических наук, младший научный сотрудник Лаборатории комплексного картографирования, Географический факультет, Московский государственный университет им. M.B. Ломоносова. ScopusID: 53863614000, Researcher ID: M-2916-2015.

Телефон: +7(495) 939-23-54 E-mail: geoigonin@gmail.com

Тикунов Владимир Сергеевич, доктор географических наук, профессор Лаборатории комплексного картограффирования, Географический фракультет, Московский государственный университет им. М.В. Ломоносова.

ScopusID: 7004523729, Researcher ID: M-1475-2015.

Телефон: +7(495) 939-13-39 E-mail: vstikunov@yandex.ru. 


\section{About the authors}

Igonin Aleksandr Ivanovich, Candidate of Geographical Sciences, Junior researcher of the Integrated Mapping Laboratory, Faculty of Geography, Lomonosov Moscow State University.

ScopusID: 53863614000, Researcher ID: M-2916-2015.

Phone: +7(495)939-23-54. E-mail: geoigonin@gmail.com.

Tikunov Vladimir Sergeevich, Doktor of Geographical Sciences, Professor of the Integrated Mapping Laboratory, Faculty of Geography, Lomonosov Moscow State University, Moscow, Russia.

ScopusID: 53863614000, Researcher ID: M-2916-2015.

Phone: +7(495) 939-13-39 E-mail: vstikunov@yandex.ru.

$\prod_{b}$

Издательство Северо-Кавказского

федерального университета.

г. Ставрополь, ул. Пушкина, 1.

Корректор - М.И. Толмачев.

Компьютерная верска - О.Г. Полевич.

Подписано в печать 29.09.2019 г. Выход в свет 10.10.2019 г. Формат $70 \times 108$ 1/16. Гарнитура Times New Roman. Бумага офсетная. Усл. печ. л. 15,5. Тираж 1000 экз. Цена 534 руб.

Отпечатано в Издательско-полиграфическом комплексе ФГАОУВО «Северо-Кавказский федеральныйуниверситет». 355029, г. Ставрополь, пр-т Кулакова, 2. 